\title{
UNIFORMIDADE DE PICADO PROCESSADO POR COLHEDORA DE FORRAGEM
}

\author{
JOSÉ F. SCHLOSSER ${ }^{1}$, MARÇAL E. DORNELLES ${ }^{2}$, EDER D. PINHEIRO ${ }^{3}$, \\ REGES DURIGON ${ }^{4}$, ALEXANDRE RUSSINI $^{5}$
}

\begin{abstract}
RESUMO: A ensilagem de plantas é prática comum no Brasil, onde se busca o armazenamento de alimentos com altos teores de energia, provenientes de plantas forrageiras para utilização em períodos de escassez. A obtenção de silagem de boa qualidade começa com a uniformidade de processamento das culturas pelas máquinas ensiladoras. Assim, este trabalho buscou avaliar a uniformidade de tamanho do picado de milho e sorgo forrageiro processado por colhedora de forragem, avaliando a metodologia para a determinação granulométrica das partículas e definindo a melhor regulagem para o uso da colhedora. Foram avaliadas duas regulagens da colhedora para tamanhos de corte entre 4 e $22 \mathrm{~mm}$, sobre as culturas de milho e sorgo forrageiro. Foi determinado que a regulagem de corte para $4 \mathrm{~mm}$ demonstrou maior uniformidade de picado em relação à regulagem de $22 \mathrm{~mm}$, valores de concentração de partículas de 63,2\% e 44,6\% para as regulagens, respectivamente, na faixa recomendada. Assim, a regulagem para $4 \mathrm{~mm}$ deve ser a recomendada para o processamento de culturas de sorgo forrageiro e milho, com uso da colhedora testada. A metodologia utilizada para a determinação da uniformidade de picado permitiu avaliação com rapidez, eficiência e simplicidade.
\end{abstract}

PALAVRAS-CHAVE: máquinas agrícolas, ensilagem, avaliação, colhedora de forragem.

\section{UNIFORMITY OF GREEN MATTER PROCESSED BY FORAGE HARVESTER}

\begin{abstract}
The process of plants ensilage is a common practice in Brazil which provides the housing of animal feeds with high level of energy through plants to use in periods of shortage. To obtain silage with good quality it is needed a uniformity during the harvesting of plants by forage harvesters. Therefore, this research aimed to evaluate the uniformity of pricked corn and sorghum harvested by forage harvester, by assessing the methodology proposed to determine the sizes of the plant particles and to define the best adjustment for using the harvester. It was evaluated two adjustments for size cutting, 4 and $22 \mathrm{~mm}$, on corn and sorghum harvesting. The adjustment of 4 $\mathrm{mm}$ showed a larger uniformity of pricked than the adjustment of $22 \mathrm{~mm}$, medium values of $63.2 \%$ and $44.6 \%$, respectively, in the recommended range. Thereby, the adjustment to $4 \mathrm{~mm}$ should be used to corn and sorghum ensilage with the evaluated harvester. The method used for determining the pricked uniformity allowed the evaluation with fastness, efficiency and simplicity.
\end{abstract}

KEYWORDS: agricultural machinery, silage, evaluation, forage harvester.

\section{INTRODUÇÃO}

Uma das formas de conservar um produto vegetal para posterior alimentação animal é por meio da ensilagem, atividade que trata do armazenamento da matéria verde em um silo, a qual irá sofrer fermentação em anaerobiose, mantendo-se assim conservada por bom tempo desde que não haja entrada de ar externo ao sistema. O uso de gramíneas tropicais para a produção de silagens é prática comum no Brasil, permitindo armazenamento de excedente de produção forrageira do

\footnotetext{
${ }^{1}$ Eng ${ }^{\circ}$ Agrônomo, Prof. Titular, Departamento de Engenharia Rural, UFSM. Santa Maria - RS. Fone: (0XX55) 3220.8175, schlosse@ccr.ufsm.br. Bolsista de produtividade CNPq.

${ }^{2}$ Eng $^{\circ}$ Agrônomo, Mestre, Programa de Pós-Graduação em Engenharia Agrícola. UFSM. Santa Maria - RS.

${ }^{3}$ Eng ${ }^{\circ}$ Agrônomo, Núcleo de Ensaios de Máquinas Agrícolas, UFSM. Santa Maria - RS.

${ }^{4}$ Eng $^{\mathrm{O}}$ Agrônomo, Professor Titular, Departamento de Engenharia Rural, UFSM, Santa Maria - RS.

${ }^{5}$ Eng ${ }^{\mathrm{o}}$ Agrônomo, Doutorando, Programa de Pós-Graduação em Engenharia Agrícola, UFSM, Santa Maria - RS.

Recebido pelo Conselho Editorial em: 21-11-2008

Aprovado pelo Conselho Editorial em: 12-12-2009
} 
período chuvoso para reduzir escassez de alimento em período crítico (CARVALHO JÚNIOR et al., 2009).

A qualidade final da silagem está diretamente ligada à coleta de boas plantas, Ao período correto de corte, com umidade ideal e processada uniformemente pelas colhedoras de forragem. Uma massa verde picada em partículas de tamanho uniforme irá permitir melhor qualidade da silagem devido a menores perdas por efluentes e por facilitar a digestibilidade do alimento pelo animal. Para NEUMANN et al. (2007), o tamanho de partículas de silagem após processamento, deve ficar entre 2 e $6 \mathrm{~mm}$, por determinar menores perdas físicas e nutricionais na desensilagem. As partículas muito pequenas não serão aproveitadas pelos ruminantes, e a concentração de partículas grandes (acima de $20 \mathrm{~mm}$ ) facilitará perdas físicas durante a desensilagem e a alimentação animal. Corroborando, BEAUCHEMIN et al. (1994) citam que o tamanho de partícula inferior a $20 \mathrm{~mm}$ favorece a disponibilidade de carboidratos solúveis, estimulando o crescimento das bactérias láticas e facilitando a compactação da silagem e o aproveitamento pelo animal. Assim, a uniformidade de partículas obtidas do corte e da trituração das forrageiras é o primeiro passo para a obtenção da chamada qualidade da forragem, expressão utilizada como referência ao valor nutritivo, resultado do processamento uniforme de boas forrageiras, correto armazenamento (ensilagem), culminando com rendimento animal satisfatório (JOBIM et al., 2007).

Para o corte e o processamento das plantas forrageiras, as máquinas ensiladoras devem ser preparadas e reguladas, disponibilizando uma gama de possibilidades de regulagens que se adaptem às mais diversas situações de trabalho e necessidades técnicas para cada cultura a ser ensilada. Todavia, grande parte das ensiladoras não realiza o seu trabalho corretamente por operarem com regulagens inadequadas ou pela falta de acompanhamento técnico, promovendo picado desuniforme ou não sendo o ideal para a cultura e resultando, ao final, em silagens de baixa qualidade ou de baixo rendimento alimentar aos animais.

Boa parte das colhedoras de forragens em uso é desenvolvida pelo processo conhecido como "tentativa-erro" (GARCIA et al., 1998), método predominante no projeto inicial de boa parte das máquinas agrícolas fabricadas no Brasil, sem passar por processo de otimização inicial do produto, o que resultaria em equipamento que atenda a todas as necessidades do produto na fase final do projeto. Para SOUZA et al. (2009), grande parcela dos fabricantes de implementos destinados a processamento de forrageiras não realiza testes satisfatórios de seus produtos. Assim, todos os testes posteriores ao projeto dessas máquinas são válidos a fim de buscar uniformidade do picado e posterior qualidade final da silagem. Durante o processamento das plantas forrageiras, há necessidade de corte, carregamento e transporte do produto (BORGES et al., 2004), atividades feitas pelas ensiladoras. Assim, as facas de corte das ensiladoras são os principais componentes da colhedora ligadas diretamente às funções antes citadas, responsáveis pela qualidade e pela uniformidade do picado (CHATTOPADHYAY \& PANDEY, 1999), pois realizam o corte do material de forma uniforme e transmitem energia cinética para lançar a massa verde para fora da máquina (GARCIA et al., 1998).

Existem diversos métodos citados para a avaliação de qualidade de picado processado por ensiladoras. Uma das metodologias, seguindo LAMMERS et al. (1996), diz respeito ao uso de conjunto de duas peneiras com orifícios de 19 e $8 \mathrm{~mm}$ de diâmetro que separam a amostra em três estratos, partículas acima de $19 \mathrm{~mm}$, entre 19 e $8 \mathrm{~mm}$ e inferiores a $8 \mathrm{~mm}$. O método foi aceito e largamente adotado nos Estados Unidos durante muitos anos, porém essa metodologia não contempla algumas condições encontradas na grande maioria das amostras colhidas no Brasil (JOBIM et al., 2007), uma vez que o tamanho das partículas aqui avaliado e desejado para a massa verde de silagem é superior ao diâmetro da maior peneira, limitando, assim, a determinação de partículas grandes (IGARASI, 2002). Assim, serão mais usuais aqueles métodos que estratifiquem as partículas em faixas de tamanho definido por peneiras, conforme a condição cultural a ser avaliada, determinando valores em percentagem de partículas em cada classe (HEINRICHS et al.,1999). 
A norma ASAE S424.1 (1998) determina, através da metodologia Wisconsin, a distribuição do tamanho de partículas de picado classificadas por meio da média geométrica do comprimento das mesmas. É feita uma pressuposição de que as partículas retidas na parte superior da malha possuem comprimento de $48 \mathrm{~mm}$. Realiza-se a separação por meio de 5 malhas $\left(\mathrm{Y}_{1}\right.$ a $\left.\mathrm{Y}_{5}\right)$, com furos diagonais relativos a $\mathrm{Y} 1=26,90 \mathrm{~mm} ; \mathrm{Y} 2=18,00 \mathrm{~mm} ; \mathrm{Y} 3=8,98 \mathrm{~mm} ; \mathrm{Y} 4=5,61 \mathrm{~mm}$, e $\mathrm{Y} 5=1,65 \mathrm{~mm}$. Essa metodologia foi utilizada por LEONARDI \& ARMENTANO (2009) utilizando diferentes misturas de concentrado e alfafa consumidas por vacas leiteiras, em que a separação do picado de alfafa era realizada por meio de malhas com furos de mesmo tamanho dos citados pela ASAE S424.1 (1998). Outros trabalhos científicos também utilizaram a referida norma para determinar o tamanho relativo das partículas de picado (ADAPA et al., 2007; WOMAC et al., 2007).

Em síntese, os estudos sobre a redução e a padronização do tamanho de partículas no processo de conservação de ensilagem de forrageiras concentram-se em três pontos importantes: melhoria qualitativa da fermentação da silagem, melhor compactação física durante a ensilagem e maior rendimento animal. Porém, o exagero na redução do tamanho de partículas pode tornar o rendimento animal ineficiente devido a perdas por efluentes e aproveitamento animal insatisfatório.

O objetivo deste trabalho foi determinar a uniformidade de tamanho do picado de milho e de sorgo forrageiro, processado pela colhedora de forragem Super JF 90 Série Prata, testar metodologia para avaliação da granulometria e definir a melhor condição de regulagem da máquina para as condições analisadas.

\section{MATERIAL E MÉTODOS}

Para a realização desta pesquisa, foram cultivadas duas parcelas, uma com milho e outra com sorgo forrageiro, culturas utilizadas em grande escala no Brasil para ensilagem e que apresentam comportamento nutricional similar (RIBEIRO et al., 2002), com tamanhos de 90 x $90 \mathrm{~m}$ cada. A área experimental possui solo do tipo Argissolo Vermelho-Amarelo argissólico (EMBRAPA, 1999), de textura média, e constituído por substrato arenito. O local do experimento foi o Câmpus da Universidade Federal de Santa Maria-RS, que se enquadra no clima Cfa2, na classificação de Köeppen, com temperaturas anuais compreendidas entre $19,2^{\circ}$ e $17,9^{\circ}$ C. A precipitação média anual está compreendida entre 1.404 e $1.769 \mathrm{~mm}$. A área experimental estava coberta com palhada de aveia e azevém (aproximadamente 2,25 $\mathrm{Mg} \mathrm{ha}^{-1}$ ), que foi dessecada 25 dias antes da semeadura das culturas de milho e sorgo forrageiro.

A semeadura de milho DOW 766 foi realizada com população de 50 mil plantas ha ${ }^{-1}$, e a do sorgo forrageiro DOW Massa 3 ocorreu com população de 180 mil plantas ha ${ }^{-1}$. A adubação foi de $270 \mathrm{~kg} \mathrm{ha}^{-1}$ de adubo fórmula NPK 4-20-18, aplicada no momento da semeadura. Como adubação nitrogenada de cobertura, foram utilizados $220 \mathrm{~kg} \mathrm{ha}^{-1}$ de ureia, com aplicação sobre as linhas de semeadura, em duas aplicações, aos 30 e 55 dias após a semeadura, em ambas as culturas. As semeaduras foram realizadas de forma direta em linhas, com espaçamento entre linhas de $900 \mathrm{~mm}$ para o milho e de $450 \mathrm{~mm}$ para o sorgo.

O corte das duas culturas para a ensilagem das plantas ocorreu em torno de 100 dias após a emergência. Nessa fase, a quase totalidade das plantas apresentava-se em estádio de grão leitoso. A definição das datas de semeadura e de corte das plantas deu-se em função dos ciclos culturais na região.

Para o processamento das forrageiras, foram utilizados um trator de marca Massey Ferguson, modelo 5310, com $77 \mathrm{~kW}(105 \mathrm{cv})$ de potência nominal no motor, e uma colhedora de forragem de marca JF, modelo Super JF 90 Série Prata. Essa colhedora possui acoplamento pelo sistema hidráulico de três pontos de engate do trator e tem acionamento pela tomada de potência $(540 \mathrm{rpm})$, exigindo potência líquida mínima de $36,7 \mathrm{~km}(50 \mathrm{cv})$ do motor do trator. A máquina apresentava rotor composto por 10 facas de corte e regulagens que permitiram processar o picado numa amplitude de 4 a $22 \mathrm{~mm}$. As facas de corte da ensiladora foram afiadas adequamente em vários 
momentos durante a coleta de dados, como forma de não haver interferência negativa desse fator nas amostras coletadas.

Para JOBIM et al. (2007), o processo de amostragem pode influenciar grandemente na avaliação da qualidade de silagens e fenos devido à tecnologia empregada durante a ensilagem. Assim, para este trabalho, os tratamentos foram definidos em função da regulagem do tamanho do picado da colhedora. Os tratamentos foram aplicados para ambas as culturas (Tabela 1).

TABELA 1. Tratamentos aplicados para a determinação da uniformidade do picado gerado pela colhedora de forragem sobre milho e sorgo. Treatments for the evaluation of pricked uniformity harvested by forage harvester on corn and sorghum.

\begin{tabular}{cl}
\hline Tratamento & \multicolumn{1}{c}{ Descrição } \\
\hline 1 & Milho picado com regulagem para tamanho de $22 \mathrm{~mm}$ \\
2 & Milho picado com regulagem para tamanho de $4 \mathrm{~mm}$ \\
3 & Sorgo picado com regulagem para tamanho de $22 \mathrm{~mm}$ \\
4 & Sorgo picado com regulagem para tamanho de $4 \mathrm{~mm}$ \\
\hline
\end{tabular}

Para cada tratamento, as amostras foram coletadas diretamente no tubo de saída da colhedora durante a colheita das forrageiras, com uso de um balde plástico, no qual a massa aproximada de $2 \mathrm{~kg}$ de matéria verde era coletado aleatoriamente sobre as linhas de cultivo e sobre toda a área experimental, para cada tratamento, e onde linhas de plantio de cabeceira das culturas foram desconsideradas. As amostras de picado foram acondicionadas em sacos de papelão e, posteriormente, submetidas à secagem à sombra sobre bandejas de fibra. Foram coletadas quatro amostras extras de cada cultura para a determinação do teor de água do picado.

Após a secagem, o picado foi classificado quanto a sua uniformidade, por meio de peneiramento do material em conjunto de peneiras circulares, composta com seis diferentes malhas $(2,5 ; 10 ; 15 ; 20 ; 25$ e $50 \mathrm{~mm})$, agitadas mecanicamente a baixa rotação e de maneira sistemática a todos os tratamentos, a fim de melhor estratificação da massa verde, seguindo recomendações e cuidados por JOBIM et al. (2007). Decidiu-se adotar procedimentos diferentes da norma ASAE S424.1 (1998), para atender aos objetivos da pesquisa de avaliar a estratificação da massa verde utilizando o conjunto de peneiras citado, e pela indisponibilidade de material exigido pela norma.

Assim, a amostragem foi realizada seguindo critérios regidos por métodos estatísticos, seguindo orientação de outros trabalhos já realizados na área. O delineamento utilizado foi o inteiramente casualizado, com cinco repetições (GOMES, 1987).

\section{RESULTADOS E DISCUSSÃO}

É possível observar, através da Figura 1, os valores percentuais retidos em cada uma das malhas da peneira para a avaliação com massa verde de milho.

A distribuição granulométrica do picado de milho, para as duas regulagens utilizadas, variou de 0,1 e $50 \mathrm{~mm}$, e a maior parte do material picado, (38,5\%), ficou com tamanho entre 5 e $10 \mathrm{~mm}$ na regulagem de $4 \mathrm{~mm}$, sendo que para a regulagem de $22 \mathrm{~mm}, 30,2 \%$ do material apresentou granulometria entre 10 e $15 \mathrm{~mm}$. 


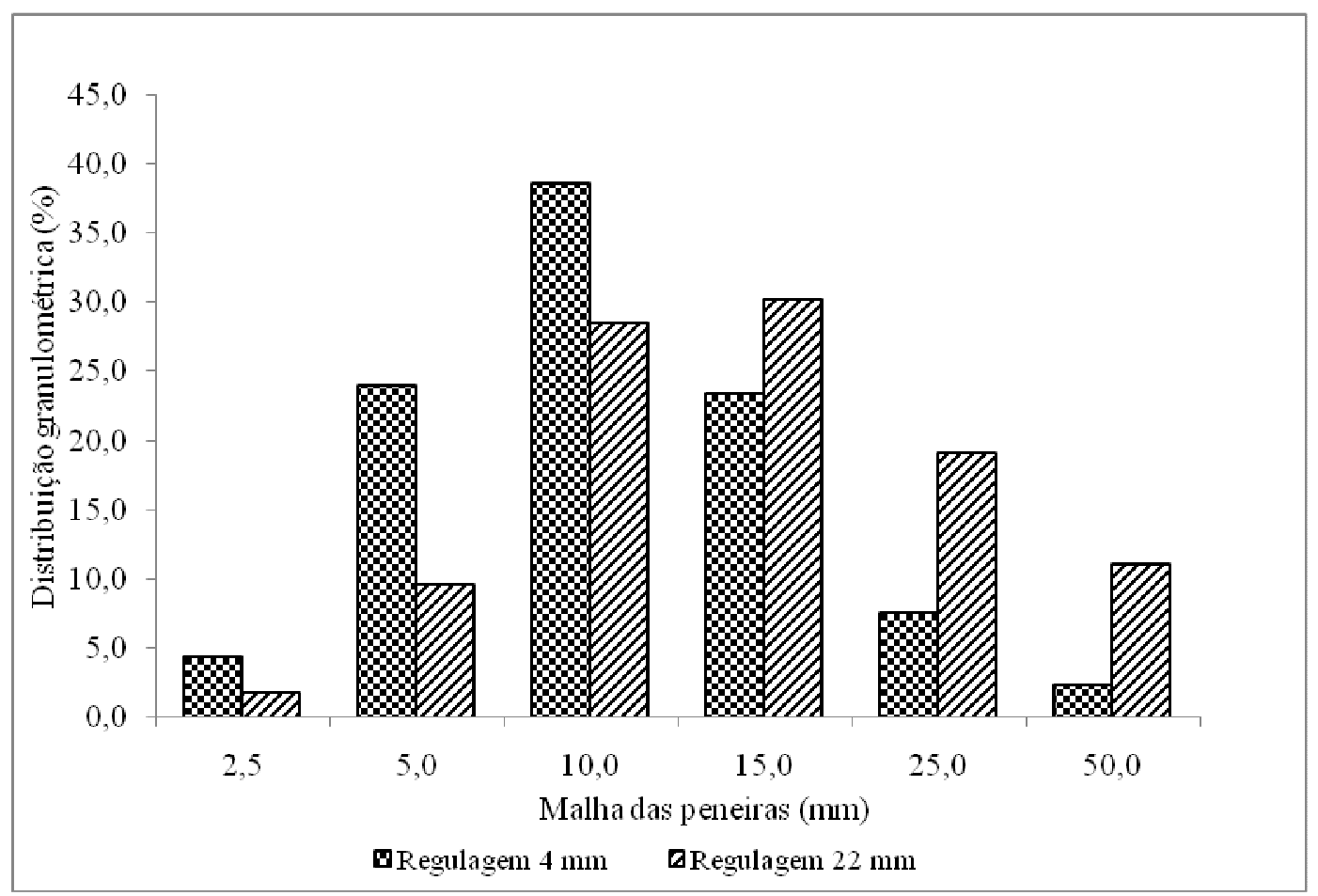

FIGURA 1. Histograma da distribuição do tamanho de picado de milho. Super JF 90 Série Prata. Histogram of sizes distribution of pricked corn. Super JF 90 Série Prata (Silver Serie).

Para os tratamentos com sorgo forrageiro, os resultados mostraram outra tendência. A maior concentração de tamanho de picados, $35 \%$ e $30 \%$, teve tamanhos entre 5 e $10 \mathrm{~mm}$ para a máquina regulada para corte de 4 e $22 \mathrm{~mm}$ de partículas, respectivamente (Figura 2).

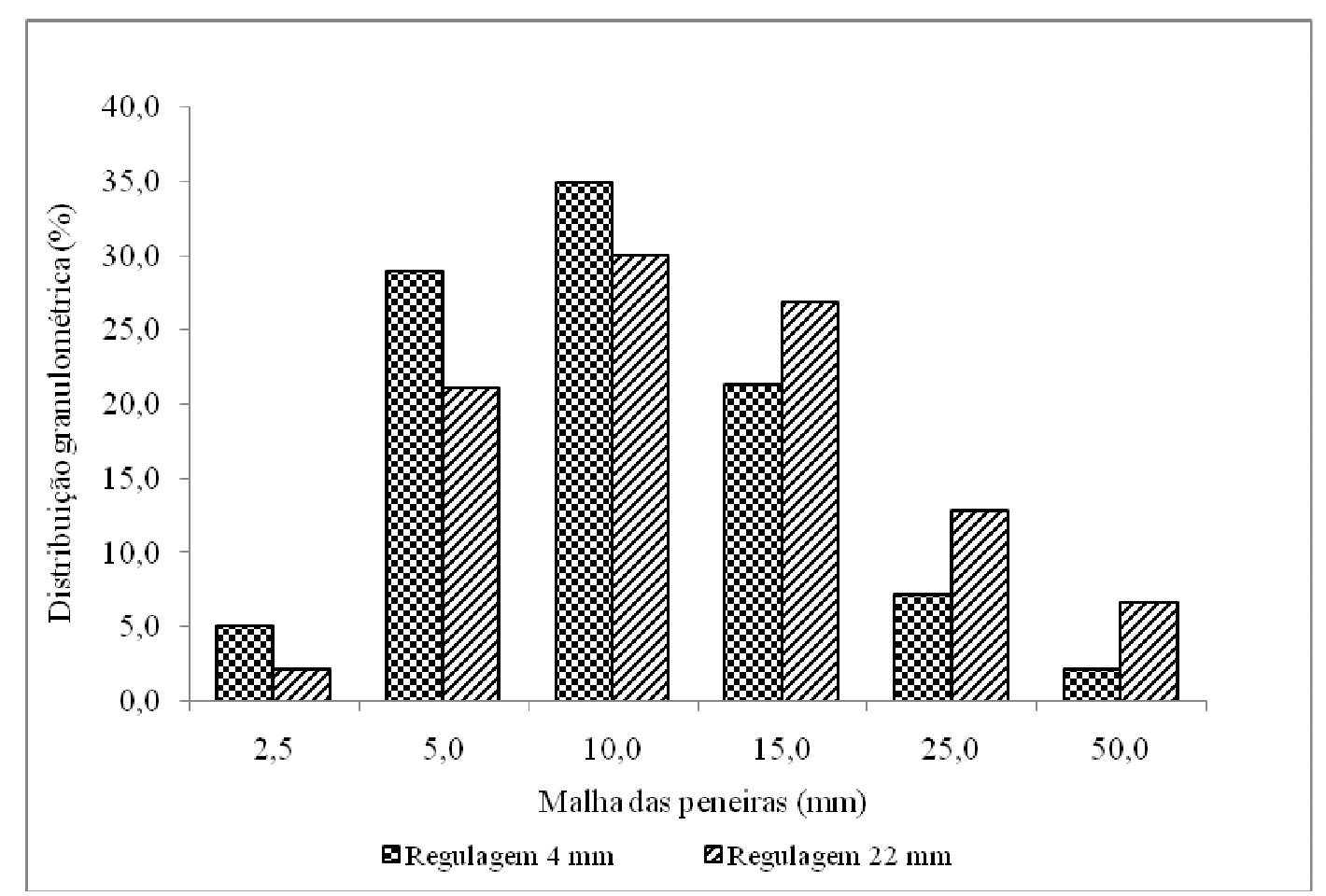

FIGURA 2. Histograma da distribuição do tamanho de picado de sorgo. Super JF 90 Série Prata. Histogram of sizes distribution of pricked sorghum. Super JF 90 Série Prata (Silver Serie). 
As curvas de distribuição granulométrica, nas duas regulagens utilizadas (Figura 3), não seguiram distribuição normal em torno da média, sendo que, para a regulagem de $22 \mathrm{~mm}$, o tamanho de picado teve maior amplitude de granulometria, ou seja, menor uniformidade.

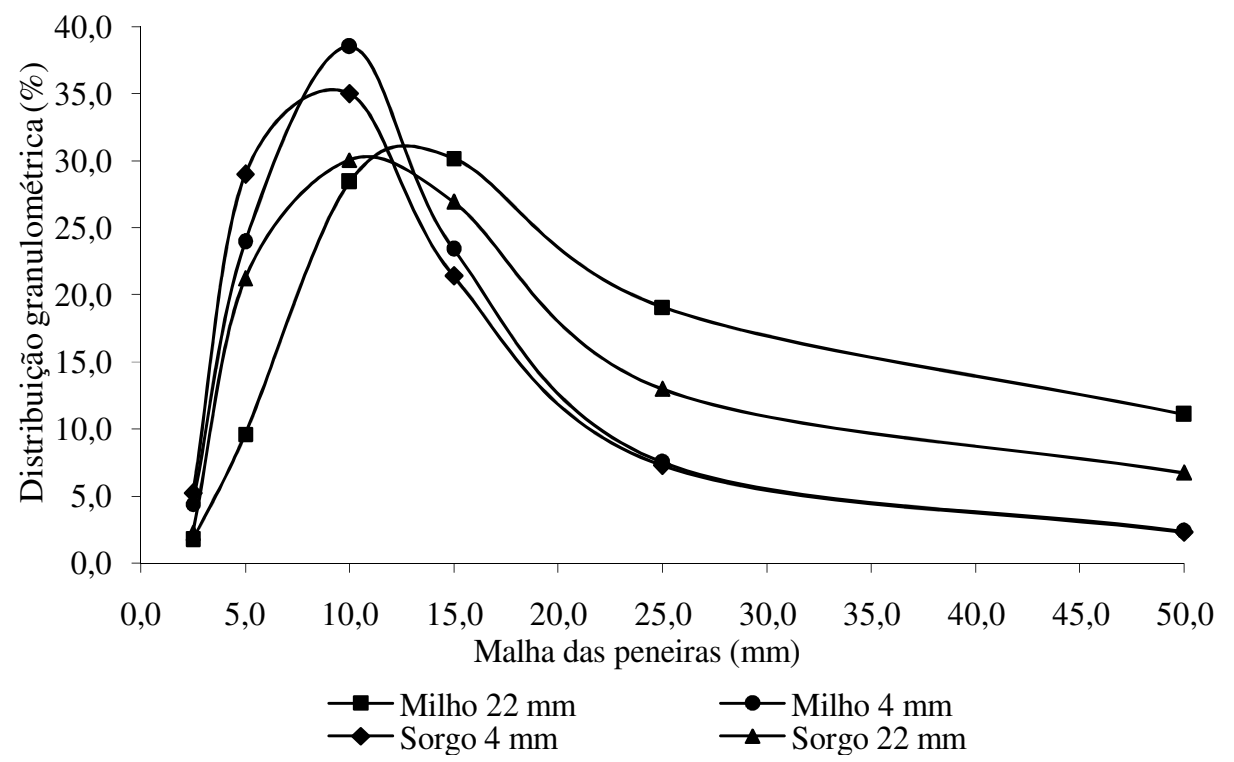

FIGURA 3. Curvas de distribuição granulométrica das partículas retidas nas peneiras. Distribution curves of particles sizes reatined on the sieves.

De maneira geral, a regulagem para processamento de $4 \mathrm{~mm}$ demonstrou maior uniformidade em relação à regulagem de $22 \mathrm{~mm}$, com maior concentração de picado na faixa ideal de partículas, conforme NEUMANN et al. (2007), apresentando valor médio de concentração de $63,2 \%$ de partículas entre 5 e $10 \mathrm{~mm}$, para ambas as culturas, contra valor médio de $44,6 \%$ de concentração de partículas para a regulagem de $22 \mathrm{~mm}$ na mesma faixa. A regulagem da colhedora de forragem para $22 \mathrm{~mm}$ demonstrou maior concentração de partículas consideradas grandes, tamanho acima de $20 \mathrm{~mm}$, devendo essa regulagem ser evitada para o processamento de culturas como milho e sorgo, por causar maiores perdas durante processo de corte e ensilagem, e menor aproveitamento ruminal durante a alimentação animal (BEAUCHEMIN et al., 1994).

A distribuição granulométrica das partículas é demonstrada a seguir (Tabela 2), na qual se constata maior amplitude de tamanhos, menor uniformidade de picado e menor concentração de partículas dentro da faixa recomendada $(5-10 \mathrm{~mm})$ para a regulagem de $22 \mathrm{~mm}$.

TABELA 2. Distribuição granulométrica de picado retido nas peneiras para os diferentes tratamentos. Granulometric distribution of the pricked retained on the sieves for the different treatments.

\begin{tabular}{llccccc}
\hline \multicolumn{7}{c}{ Material Coletado (\%)* } \\
\hline \multirow{2}{*}{ Tratamento } & \multicolumn{5}{c}{ Malha das Peneiras } \\
\cline { 2 - 6 } & $2,5 \mathrm{~mm}$ & $5 \mathrm{~mm}$ & $10 \mathrm{~mm}$ & $15 \mathrm{~mm}$ & $25 \mathrm{~mm}$ & $50 \mathrm{~mm}$ \\
\hline Milho / $4 \mathrm{~mm}$ & $4,4 \mathrm{~cd}$ & $23,9 \mathrm{abc}$ & $38,5 \mathrm{a}$ & $23,4 \mathrm{ab}$ & $7,5 \mathrm{bcd}$ & $2,3 \mathrm{~d}$ \\
Milho / $22 \mathrm{~mm}$ & $1,7 \mathrm{c}$ & $9,6 \mathrm{c}$ & $28,4 \mathrm{ab}$ & $30,2 \mathrm{a}$ & $19,0 \mathrm{abc}$ & $11,1 \mathrm{bc}$ \\
Sorgo / $4 \mathrm{~mm}$ & $5,2 \mathrm{~b}$ & $29,0 \mathrm{a}$ & $35,0 \mathrm{a}$ & $21,4 \mathrm{ab}$ & $7,3 \mathrm{~b}$ & $2,3 \mathrm{~b}$ \\
Sorgo / $22 \mathrm{~mm}$ & $2,2 \mathrm{~b}$ & $21,2 \mathrm{ab}$ & $30,0 \mathrm{a}$ & $26,9 \mathrm{a}$ & $12,9 \mathrm{ab}$ & $6,7 \mathrm{~b}$ \\
\hline
\end{tabular}

*Médias seguidas de mesma letra não diferem significativamente entre si, a 5\% de probabilidade, pelo teste de Tukey. A análise estatística compara valores na mesma linha.

Embora determinada uniformidade granulométrica não seja satisfatória, é interessante ressaltar que a colhedeira utilizada era seminova, e por não termos tido auxílio da empresa fabricante no sentido de preparação da máquina, isso pode ter influenciado na não uniformidade do 
picado. Mesmo com poucas horas de uso, as facas de corte poderiam estar apresentando desgaste que possa ter comprometido a regularidade do corte, mesmo sendo afiadas em momentos anteriores ao corte.

A umidade determinada das amostras de massa verde foi de $74 \%$ e $75 \%$ para culturas de milho e sorgo, respectivamente, valores próximos à faixa de umidade recomendada para corte, entre 72 e $73 \%$ (MORAES, 1995).

\section{CONCLUSÕES}

A distribuição granulométrica do picado apresentou resultado pouco satisfatório, devido à grande amplitude de tamanhos resultantes do processamento das culturas de sorgo e milho.

A regulagem para $4 \mathrm{~mm}$ de corte apresentou maior uniformidade e percentual dentro da faixa recomendada de tamanho de partículas e deve ser a regulagem preferida para o processamento de culturas de sorgo e de milho com a colhedora testada.

A metodologia utilizada para a determinação da uniformidade de picado processado pela colhedora permitiu avaliação da granulometria do picado com rapidez, eficiência e simplicidade.

\section{REFERÊNCIAS}

ADAPA, P.; SCHOENAU, G.; TABIL, L.; SOKHANSANJ, S.; SINGH, A. Compression of fractionated sun-cured and dehydrated alfalfa chops into cubes-Specific energy models.

Bioresource Technology, Kidlington, v.98, n.1, p.38-45, 2007.

ASAE. AMERICAN SOCIETY OF AGRICULTURAL ENGINEERS. Method of determining and expressing particle size of chopped forage materials by screening. St. Joseph, 1998. p.562-564. (ASAE Standards S424.1)

BEAUCHEMIN, K.A.; McALLISTER, T.A.; DONG, Y.; FARR, B.I.; CHENG, K.J. Effects of mastication on digestion of whole cereal grains by cattle. Journal of Animal Science, Stanford, v.72, n.1, p.236-246, 1994.

BORGES, P.H.M.; NIIYAMA, O.K.; BRAGA JÚNIOR, R.A.; VOLPATO, C.E.S.; RAVELO, G.F.; SANTOS, L.M. dos. Análise dos ciclos de tensões em colhedoras de forragens. Engenharia Agrícola, Jaboticabal, v.24, n.3, p.704-711, 2004.

CARVALHO JÚNIOR, J. N. de C.; PIRES, A.J.V.; SILVA, F.F. da; VELOSO, C.M.; SANTOSCRUZ, C.L. dos; CARVALHO, G.G.P. de. Desempenho de ovinos mantidos com dietas com capim-elefante ensilado com diferentes aditivos. Revista Brasileira de Zootecnia, Viçosa - MG, v.38, n.6, p.994-1.000, 2009.

CHATTOPADHYAY, P. S.; PANDEY, K.P. Effect of knife and operational parameters on energy requirement in flail forage harvesting. Journal of Agricultural Engineering Research, Silsoe, v.73, n.1, p.3-12, 1999.

EMBRAPA. EMPRESA BRASILEIRA DE PESQUISA AGROPECUÁRIA. Sistema brasileiro de classificação de solos. Brasília, 1999. 412 p.

GARCIA, R.F.; QUEIROZ, D.M.; DIAS, G.P. Análise de tensões na faca de corte de uma colhedora de forragem. Revista Brasileira de Engenharia Agrícola e Ambiental, Campina Grande, v.2, n.2, p.219-223, 1998.

GOMES, F.P. A Estatística moderna na pesquisa agropecuária. 3.ed. Piracicaba: Potafós, 1987. $162 \mathrm{p}$.

HEINRICHS, A.J.; BUCKMASTER, D.R.; LAMMERS, B.P. Processing, mixing and particle size reduction of forages for dairy cattle. Journal of Animal Sciense, Stanford, v.77, n.1, p.180-186, 1999. 
IGARASI, M.S. Controle de perdas na ensilagem de Capim Tanzânia (Panicum Maximum cv. Tanzânia) sob efeitos do teor de matéria seca, do tamanho de partículas, da estação do ano e da presença do inoculante bacteriano. 2002.132 f. Dissertação (Mestrado em Ciência Animal e Pastagens) - Escola Superior de Agricultura “Luiz de Queiroz", Universidade de São Paulo, Piracicaba, 2002.

JOBIM, C.C.; NUSSIO, L.G.; REIS, R.A.; SCHMIDT, P. Avanços metodológicos na avaliação da qualidade da forragem conservada. Revista Brasileira de Zootecnia, Viçosa - MG, v.36, p.101-119, 2007. Suplemento especial.

LAMMERS, B.P.; BUCKMASTER, D.R.; HEINRINCHS, A.J. A simple method for the analysis of particle size of forage and total mixed rations. Journal of Dairy Science, Savoy, v.79, n.5, p.922928, 1996.

LEONARDI, C.; ARMENTANO, L.E. Effect of quantity, quality, and length of alfalfa hay on selective consumption by dairy cows. Journal of Dairy Science, Stanford, v.86, p.3.922-3.929, 2009.

MORAES, Y.J.P. Forrageiras: conceitos, formação e manejo. Guaiba: Guaiba Agropecuária, 1995. $215 \mathrm{p}$.

NEUMANN, M.; MÜHLBACH, P.R.F.; NÖRNBERG, J.L.; RESTLE, J.; OST, P.R. Efeito do tamanho de partícula e da altura de colheita das plantas de milho (Zea mays L.) sobre as perdas durante o processo fermentativo e o período de utilização das silagens. Revista Brasileira de Zootecnia, Viçosa - MG, v.36, n.5, p.1.395-1.405, 2007.

RIBEIRO, E.L. de A.; ROCHA, M.A. da; MIZUBUTI, I.Y.; SILVA, L. das D.F. da. Silagens de girassol (Helianthus annus L.), milho (Zea mays L.) e sorgo (Sorghum bicolor (L.) Moench) para ovelhas em confinamento. Ciência Rural, Santa Maria, v.32, n.2, p.299-302, 2002.

SOUZA, L.H. de; VIEIRA, L.B.; DIAS, G.P.; REGAZZI, A.J. Capacidade de produção e consumo específico de energia em picadoras forrageiras tipo desintegrador/picador/moedor. Revista Brasileira de Engenharia Agrícola e Ambiental, Campina Grande, v.13, n.1, p.88-93, 2009.

WOMAC, A.R.; IGATHINATHANE, C.; BITRA, P.; MIU, P.; YANG, T.; SOKHANSANJ, S.; NARAYAN, S. Biomass pre-processing size reduction with instrumented mills. In: ASABE ANNUAL INTERNATIONAL MEETING, 2007, Minessota. Paper Number 076046. 